\title{
Crosslinked agarose encapsulated sorbents resistant to steam sterilization. Preparation and mechanical properties
}

Henk W. M. de Koning, Rob A. F. M. Chamuleau, and Adriaan Bantjes

Department of Chemical Technology, Biomaterials Section. Twente University of Technology, Enschede, The Netherlands

The application of agarose in hemoperfusion is hampered by the lack of a suitable sterilization method. A technique has been developed for the crosslinking of agarose encapsulated sorbents by the reaction with 1,3-dichloro-2-propanol (DCP) under strong alkaline conditions. A twofold molar excess of DCP with respect to agarose and an equimolar amount of sodium hydroxide at a concentration of $0.3 \mathrm{~mol} / \mathrm{L}$ with a reaction time of $1-4 \mathrm{~h}$ at $50^{\circ} \mathrm{C}$ are found to be the optimal conditions. The compressive strength of crosslinked beads is increased by a factor of 4. Agarose capsules are found to degrade by the influence of $\gamma$ radiation, but are resistant to steam sterilization at $134^{\circ} \mathrm{C}$ during at least $30 \mathrm{~min}$ when crosslinked.

\section{INTRODUCTION}

In recent years, growing interest has been observed in the application of agarose in hemoperfusion. Plotz et al. ${ }^{1}$ described the removal of bilirubin from whole blood by albumin-conjugated agarose gel. Rawer, Leber, and Schuetterle ${ }^{2}$ described the specific removal of digoxin by agarose-bound antibodies. The problems these authors encountered, concerning hemodynamics and microparticle release, can be attributed to the extremely small bead diameter $^{3}(45-160 \mu)$ of the gel used in these studies. These problems have been solved by Brunner and co-workers ${ }^{4-6}$ using preparations of enlarged beads* with diameters ranging $2-10 \mathrm{~mm}$. The fields of application can be separated into two major categories:

(1) Hemoperfusion through agarose beads containing immobilized enzymes or antibodies. In these cases, the agarose bead acts as a carrier matrix for the enzymes or antibodies. Enzymatic modifications of toxic compounds into less toxic or more hydrophilic substances, or specific complexation to the antibody, is the detoxification route.

(2) Hemoperfusion through agarose capsules* containing sorbents. In

- Laboratory for Experimental Internal Medicine, Wilhelmina Gasthuis, University of Amsterdam, Amsterdam, The Netherlands.

* In this work, agarose beads without any sorbent content are denoted as beads, while capsules containing sorbents are referred to as capsules. 
these applications the agarose acts as a coating material, intended to improve the blood compatibility of the sorbent encapsulated. Adsorption of the toxins on to the sorbents is the detoxification route.

In all cases the relatively good blood compatibility, the high permeability for the toxins to be removed ${ }^{4}$ and the possibility of the encapsulation of powdered sorbents are the major advantages. There are, however, two serious problems which must be solved before clinical trials can be performed. The mechanical strength is not very high. This implies the possible formation of microparticles due to rupture of the capsules by mechanical causes. The major problem, however, is the sterilization.

Steam sterilization is not possible since the capsules melt at a temperature of $90^{\circ} \mathrm{C}$. Sterilization with chemical agents is not preferable since these chemicals can adsorb to the encapsulated sorbents and could be released during clinical use. Since the parental product of agarose, agar-agar, is not resistant to $\gamma$ radiation, ${ }^{7}$ this technique is not favorable.

Sepharose-CL is a commercially available product prepared from agarose by the reaction with 2,3-dibromopropanol under alkaline condition. This yields a crosslinked gel with substantially the same porosity as the parent gel, but with greatly increased thermal and mechanical stability, which can be sterilized repeatedly by autoclaving at $120^{\circ} \mathrm{C}$ without significant changes in properties. ${ }^{3}$ This knowledge prompted us to develop a modified method with 1,3-dichloro-2-propanol as the crosslinking agent, in order to produce crosslinked agarose capsules with an increased mechanical strength and resistant to steam sterilization. We report here on the preparation of agarose beads and capsules and the factors which influence the mechanical properties such as agarose concentration and sorbent content. Since compression is the predominant force acting on the capsules at working conditions, the compressive strength has been adopted as a criterium. Furthermore, the optimization of the crosslinking conditions such as reaction time, alkaline concentration, and amounts of crosslinker are presented. Finally, the effects of autoclaving and $\gamma$ radiation on the mechanical properties will be presented.

\section{MATERIALS AND METHODS}

Agarose in powder form (type C) and in beaded gel form (Sepharose 6B) were obtained from Pharmacia Fine Chemicals (Uppsala, Sweden). The sorbents employed were Norit RBX-1, extruded granular activated charcoal (Norit, Amersfoort, The Netherlands). Amberlite XAD 4, neutral polystyrene-based resin (Serva, Heidelberg, Germany). Imac C12, strong acidic cation-exchange resin was a gift of AKZO-Chemie (Amsterdam, The Netherlands). All sorbents were ground in a vibrating disk mill (Siebtechnik, Mühlheim/Rhur, Germany). The fractions passing through a ASTM 140 mesh $(0.1 \mathrm{~mm})$ sieve were used for further experiments. 


\section{Capsule preparation}

The method employed was very similar to the procedure described by Holloway, Harstick, and Brunner. ${ }^{4}$ Suspensions of gels, together with appropriate amounts of sorbents were heated in a waterbath at $95^{\circ} \mathrm{C}$ until they had melted into a uniform viscous liquid. The mixture was drawn into a syringe and injected dropwise into a cold mixture of toluene $(1000 \mathrm{~mL})$, chloroform $(400 \mathrm{ml})$, and hexane $(200 \mathrm{~mL})$. This mixture had a density similar to that of the hot beads, but less than that of the cold solidified beads, allowing sufficient time for the beads to cool before contacting the vessel wall. When activated charcoal or cation-exchange resins were encapsulated, the hexane was omitted, since these capsules had higher densities than beads. In the original mixture, the capsules sink too fast. This leads to agglomeration and deformation of the capsules. When XAD 4 was encapsulated, the amount of chloroform was reduced to $200 \mathrm{~mL}$, since these capsules have a lower density and tend to float on the original mixture, which also leads to agglomeration. The capsules were isolated from the organic phase by filtration and were washed thoroughly with distilled water. The organic mixture could be reused after drying with anhydrous magnesium sulphate.

\section{Compressive strength measurements}

A device has been developed to measure the weight under which an individual bead ruptures. The apparatus, schematically shown in Figure 1, consists of a lever, and the bead to be tested is compressed between the end of the right arm of the lever and a balance. By slowly moving the left arm upwards by means of a screw mechanism, the pressure on the capsule increases. The

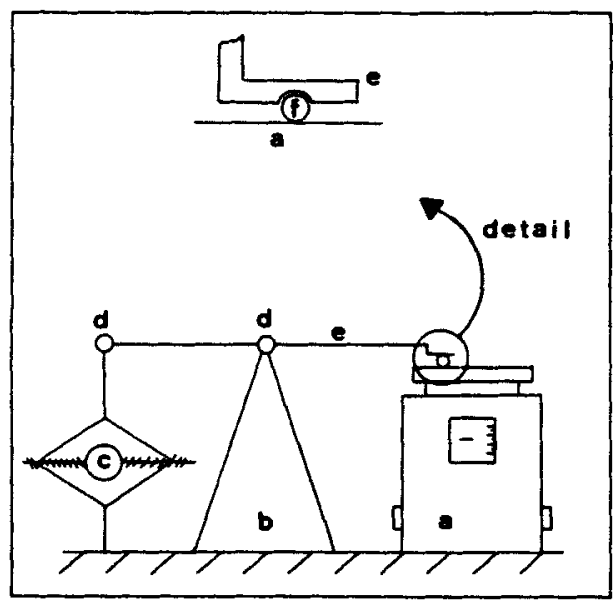

Figure 1. Schematic representation of compressive-strength measurement device consisting of (a) a balance, (b) support, (c) screw mechanism, (d) joints, (e) lever arms, and (f) the bead to be tested. 
rupture of the bead is observed visually, and the weight indicated by the balance is registered. In order to obtain statistically meaningful results, at least 20 measurements were performed for each experiment. The samples used had a diameter of $4.3 \pm 0.35 \mathrm{~mm}$ (mean \pm S.D.).

\section{Effects of agarose concentration and sorbent content on compressive strength}

Powdered agarose was prepared as 1, 2, 3, 4, and $6 \% \mathrm{w} / \mathrm{w}$ suspensions in cold distilled water. Beads with a mean diameter of $4.3 \mathrm{~mm}$ were prepared as described above. The same series was prepared from Sepharose 6B gel by addition of appropriate amounts of cold distilled water. The compressive strength was measured.

Capsules were prepared from agarose powder $(4 \% \mathrm{w} / \mathrm{w})$ containing activated charcoal or Imac $\mathrm{C} 12$ by addition of $0.035,0.10,0.20,0.50$, and $0.80 \mathrm{~g}$ sorbent (wet weight) to each gram of gel. Amberlite XAD 4 was encapsulated with amounts of $0.035,0.15,0.30,0.50$, and $0.90 \mathrm{~g}$ (wet weight) to each gram of gel. The compressive strength was measured.

\section{Crosslinking experiments}

Beads prepared from agarose powder $(6 \% \mathrm{w} / \mathrm{w})$ were crosslinked by reaction with 1,3-dichloro-2-propanol (DCP) under strong alkaline conditions. A series of crosslinking experiments were performed in order to obtain the optimal conditions. In all experiments a net weight of $1.5 \mathrm{~g}$ of beads was added to 10 $\mathrm{mL}$ of a solution of $\mathrm{NaOH}$ in distilled water. The concentration of $\mathrm{NaOH}$ ranged $0.05-5.0 \mathrm{~mol} / \mathrm{L}$. An equimolar amount of $D C P$ with respect to agarose hydroxyl groups was added $(0.50 \mathrm{~mL})$. The same series of experiments was repeated with, respectively, $0.1,0.25,0.5,1.0$, and $2.0 \mathrm{~mL}$ of DCP. The reactions were allowed to proceed for various times ranging $30 \mathrm{~min}-16 \mathrm{~h}$, with continuous agitation at $52^{\circ} \mathrm{C}$. After the reaction time had completed, the beads were washed with water until the effluent had become neutral. The compressive strength was measured. In addition, the beads were exposed to boiling water for 5-10 min as a screening test for increased thermal stability.

The same procedure was followed with a tenfold excess of DCP $(0.5 \mathrm{~mL})$ and equimolar amounts of $\mathrm{NaOH}$ with various concentration and, as a consequence, various volumes of solution $(09.3 \mathrm{~mol} / \mathrm{L}, 40 \mathrm{~mL}-2.4 \mathrm{~mol} / \mathrm{L}, 5 \mathrm{~mL})$.

Capsules containing ion-exchange resin, activated charcoal, or Amberlite $\mathrm{XAD} 4(33 \% \mathrm{w} / \mathrm{w}$ sorbent, $4 \% \mathrm{w} / \mathrm{w}$ agarose powder) were crosslinked with the following conditions: capsules $3.4 \mathrm{~g}, \mathrm{NaOH} 10 \mathrm{~mL}, 0.3 \mathrm{~mol} / \mathrm{L}, \mathrm{DCP} 0.1 \mathrm{~mL}$, temperature $50^{\circ} \mathrm{C}$, reaction time $1-8 \mathrm{~h}$. The compressive strength was measured, and the capsules were exposed to boiling water.

Beads prepared from agarose powder $(1,2,3,4$, and $6 \% \mathrm{w} / \mathrm{w})$ were crosslinked with $10 \mathrm{~mL} \mathrm{NaOH} 0.3 \mathrm{~mol} / \mathrm{L}$, and $0.1 \mathrm{~mL} \mathrm{DCP}$ at $50^{\circ} \mathrm{C}$ for $2 \mathrm{~h}$. The amounts of be ads were, respectively, $9,4.5,3,2.25$, and $1.5 \mathrm{~g}$. The compressive strength was measured. 


\section{Sterilization procedures}

About $15 \mathrm{~g}$ of crosslinked beads (4\% agarose powder) and uncrosslinked beads $(2,4$, and $6 \%$ agarose gel) were added to glass ampules containing distilled water. The ampules were irradiated by a ${ }^{60} \mathrm{Co}$ source (Interuniversitair Reactor Instituut, Delft, The Netherlands) at a dose rate of $0.16 \mathrm{Mrad} / \mathrm{h}$ to a total dose of $0.5,1,1.5$, and $2.5 \mathrm{Mrad}$. The same experiments were carried out with uncrosslinked beads $(6 \% \mathrm{gel})$ in the absence of oxygen. In these latter experiments, glass ampules, containing $15 \mathrm{~g}$ of beads in distilled water, were degassed by repeated evacuation with nitrogen gas at room temperature. The ampules were sealed under vacuum. After irradiation the compressive strength was measured.

About $15 \mathrm{~g}$ of crosslinked beads (4\% agarose powder) and capsules containing activated charcoal or Imac $\mathrm{C} 12$ (33\%) were autoclaved in open glass ampules at $122^{\circ} \mathrm{C}$ for 15,60 , and $120 \mathrm{~min}$. After allowing the samples to cool to room temperature, the compressive strength was measured. In addition, beads were tested in the same way at $134^{\circ} \mathrm{C}$ for $30 \mathrm{~min}$.

\section{RESULTS}

With the methods described, spherical beads or capsules with a diameter between 4 and $5 \mathrm{~mm}$ are prepared in a reproducible manner (Fig. 2). By injecting the molten gel in a continuous manner through a small orifice $(0.5 \mathrm{~mm})$ into a stirred vessel containing the cold organic mixture, smaller capsules are prepared. In this manner the production rate is greatly increased and approximately $90 \mathrm{wt}$.\% of the capsules have a diameter between 0.85 and 3.35 $\mathrm{mm}$. With the latter system, the maximum practical agarose concentration appears to be $4 \% \mathrm{w} / \mathrm{w}$. Higher concentrations produce melts with too high a viscosity, which leads to the formation of larger irregularly shaped capsules.

The compressive strength of beads is proportional to the agarose concen-
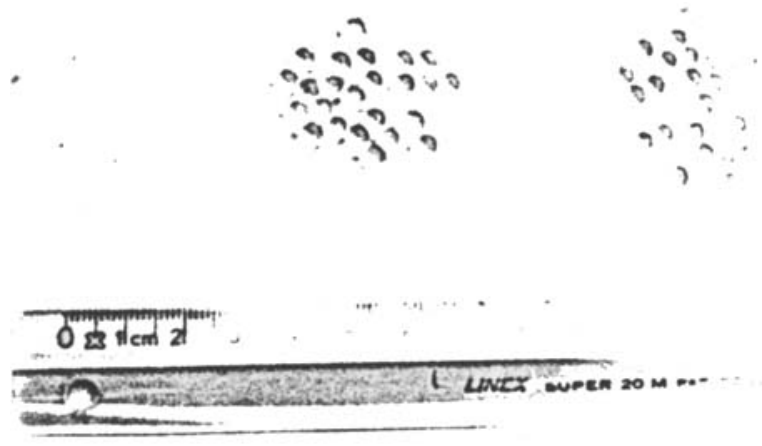

Figure 2. Photographs of beads (left) before and (middle) after crosslinking and after steam sterilization at (left) $134^{\circ} \mathrm{C}$. 


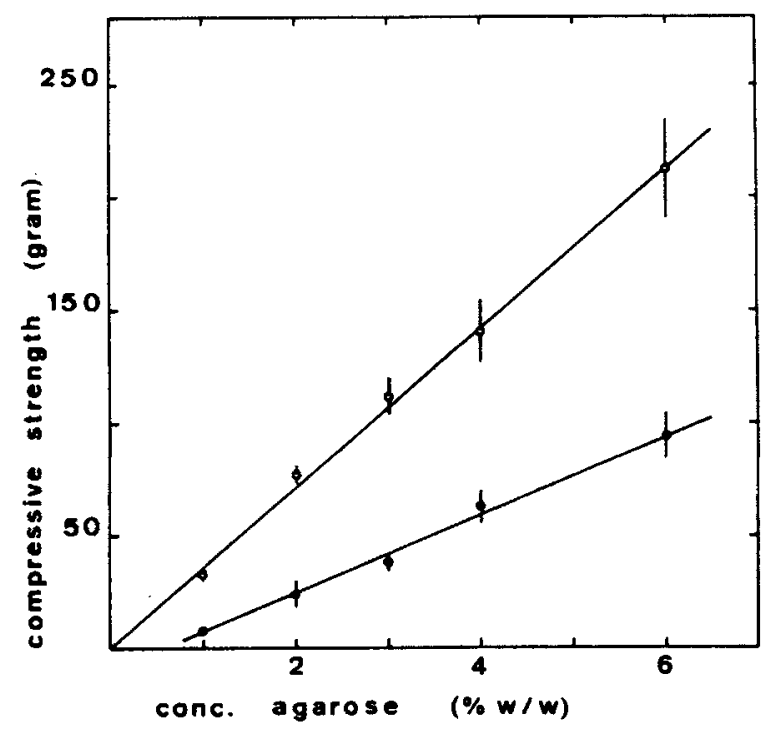

Figure 3. Dependency of the compressive strength on the agarose concentration of beads prepared from $(0)$ agarose powder and $(\bullet)$ prebeaded gel.

tration of the gel (Fig. 3). Beads prepared from agarose powder as starting material are approximately twice as strong as beads prepared from the prebeaded Sepharose gel. The standard deviation in the compressive strength measurements is $5-10 \%$ in all cases.

When sorbents are introduced in the beads, the compressive strength is

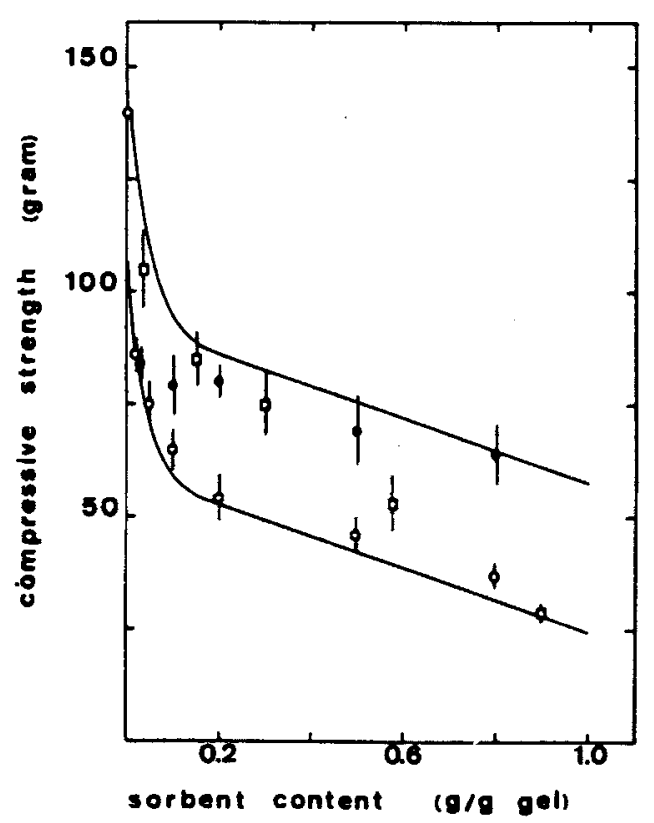

Figure 4. Influence of the amount of sorbent encapsulated on the compressive strength of capsules. (๑) activated charcoal, (O) Imac C12 cation exchange resin, and (ם) Amberlite XAD 4. 


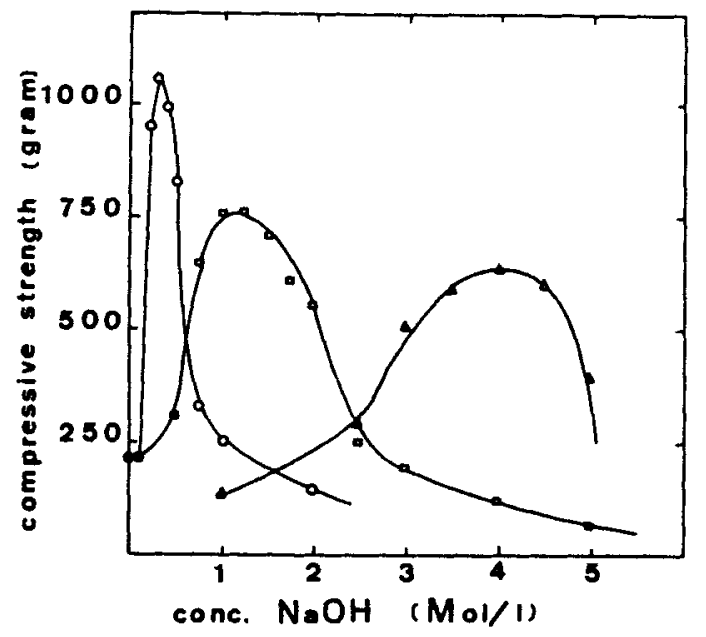

Figure 5. Compressive strength after crosslinking. Influence of alkaline concentration and excess of crosslinker. DCP excess: (O) 2-fold, ( $(\square) 10$-fold, and $(\Delta) 35$-fold. Open symbols refer to beads resistant to boiling water.

reduced to $30-50 \%$ of the value of the parent bead, slightly dependent on the kind of sorbent and the amount of sorbent encapsulated (Fig. 4). With other agarose concentrations or prebeaded gel as starting material, very similar results are obtained.

\section{Crosslinking}

After crosslinking the compressive strength (CS) is markedly increased as compared with the value observed for untreated beads $\left(\mathrm{CS}_{u}\right)$. The beads are insoluble in boiling water after crosslinking. The reaction is completed within

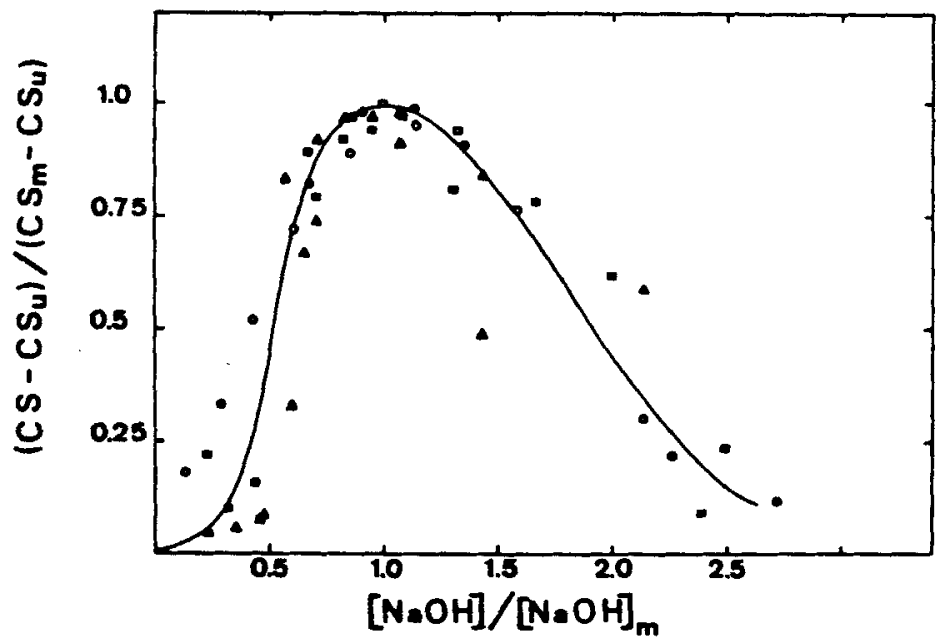

Figure 6. Dependency of the compressive strength on the sodium hydroxide concentration. Mol DCP/mol agarose $\mathrm{OH}$ group: (4) $17.8,(\mathbf{m}) 8.9,(\bullet)$ 4.4, ( $\Delta) 2.22$, (D) 0.9 , and $(0) 0.45$; CS: compressive strength, $\mathrm{CS}_{m}$ : CS at maximum strength, and $\mathrm{CS}_{u}$ : CS untreated. 


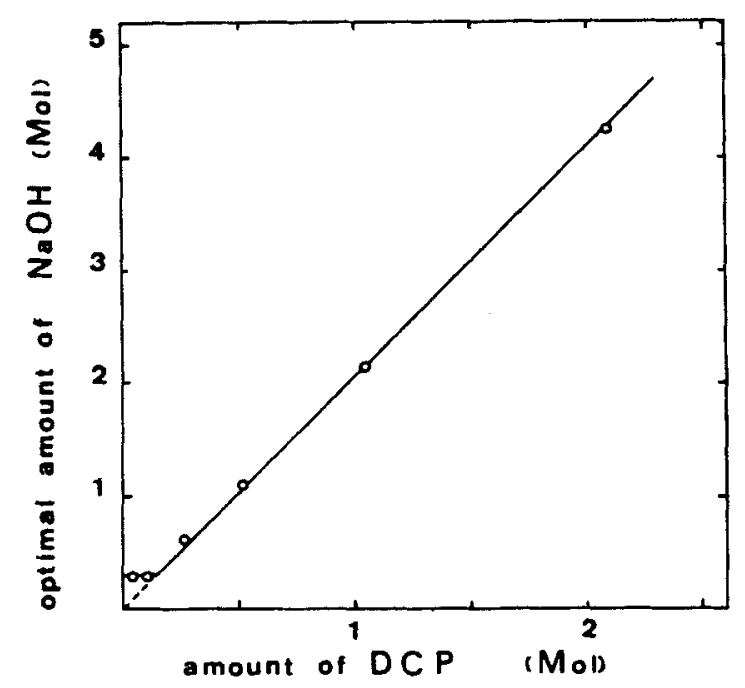

Figure 7. Relation between optimal amount of $\mathrm{NaOH}$ and the amount of DCP.

30-60 $\mathrm{min}$. This is concluded because the beads are completely insoluble in boiling water, while prolongation of the reaction time does not lead to an increase in CS. When sorbents are encapsulated, the reaction proceeds slower. An increase in CS is observed until the reaction has proceeded 2-4 h. At. shorter reaction times the central parts of crosssectioned capsules are still soluble in boiling water. In all cases small excesses of crosslinker require the longest reaction time. The procedure has no noticeable effect on the dimensions of the beads or capsules. The slightly opaque beads, however, become transparent by the crosslinking reaction and are more rubberlike (Fig. 2).

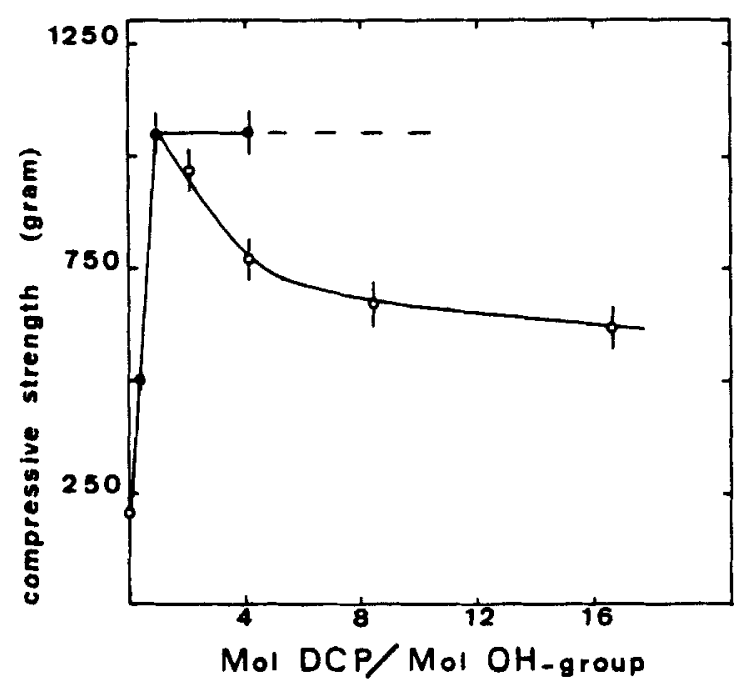

Figure 8. Dependency of the optimal strength on the excess of DCP. (-) $[\mathrm{NaOH}]=0.3 \mathrm{~mol} / \mathrm{L}$ and $(0)[\mathrm{NaOH}]=$ optimal concentration as in Figure 5. 
TABLE I

Influence of Alkaline Concentration on the Compressive Strength at Stoechiometric Conditions

\begin{tabular}{cccc}
\hline$[\mathrm{NaOH}](\mathrm{mol} / \mathrm{L})$ & Volume $(\mathrm{mL})$ & $\mathrm{CS}(\mathrm{g})$ & S.D. $(\mathrm{g})$ \\
\hline 2.4 & 5 & 757 & 39 \\
1.2 & 10 & 857 & 42 \\
0.6 & 20 & 880 & 59 \\
0.3 & 40 & 1048 & 71 \\
\hline
\end{tabular}

Figure 5 shows the effect of alkaline concentration ( $[\mathrm{NaOH}])$ on the compressive strength for a 2-fold, 10 -fold, and 35-fold excess of DCP. It is obvious that $[\mathrm{NaOH}]_{m}$, the concentration required for the maximum compressive strength $\left(C_{m}\right)$ is strongly dependent on the amount of DCP used. The actual value of $\mathrm{CS}_{m}$ decreases with increasing excess of crosslinker, and as a consequence, with increasing $[\mathrm{NaOH}]_{m}$.

When the relative increase in CS, defined as $\left(\mathrm{CS}-\mathrm{CS}_{u}\right) /\left(\mathrm{CS}_{m}-\mathrm{CS}_{u}\right)$ is plotted as a function of the relative alkaline concentration $[\mathrm{NaOH}] /[\mathrm{NaOH}]_{m}$, all data can be grouped into one uniform graph as shown in Figure 6. It is clear that $[\mathrm{NaOH}]$ is not very critical. Considering an experimental error of $10 \%$ in the CS measurements, a deviation of $10-20 \%$ from the optimal $[\mathrm{NaOH}]$ can be accepted without major reductions of mechanical properties.

The amount of $\mathrm{NaOH}$ required for optimal strength is related to the amount of DCP used as shown in Figure 5. This relation is elucidated in Figure 7. The reaction proceeds in a stochiometric manner. Deviations are observed only when small amounts of DCP are used. Since the reaction proceeds only at $\mathrm{pH}>13$, this deviation is likely to be a reflection of the experimental setup, using the same reaction volume in all cases.

It is apparent from Figure 8 that a twofold excess of DCP yields an optimal strength. An increase in the excess of DCP results in a decrease in $C_{m}$. This phenomenon is due to the increased $[\mathrm{NaOH}]$. When the reaction is allowed to proceed with a tenfold excess of DCP at stochiometric conditions, but with reduced $[\mathrm{NaOH}](0.3 \mathrm{~mol} / \mathrm{L})$, no reduction in $\mathrm{CS}_{m}$ is observed (Table I, Fig. 8). The optimal CS is increased by a factor of approximately 5 as compared with $\mathrm{CS}_{u}$. Similar ratios are found when other agarose concentrations are employed and when sorbents are encapsulated.

\section{Sterilization}

The agarose beads degrade under the influence of $\gamma$ radiation (Fig. 9). In all cases a linear relation was found between CS and the square root of the dose applied. Especially at higher doses, the beads become sticky and show a more pronounced deformation under pressure as compared with beads which had not been irradiated. No significant influence of oxygen could be observed.

However, crosslinked beads and capsules were completely unaffected by the influence of steam at $122^{\circ} \mathrm{C}$ during at least $2 \mathrm{~h}$ (Fig. 10). The dimensions 


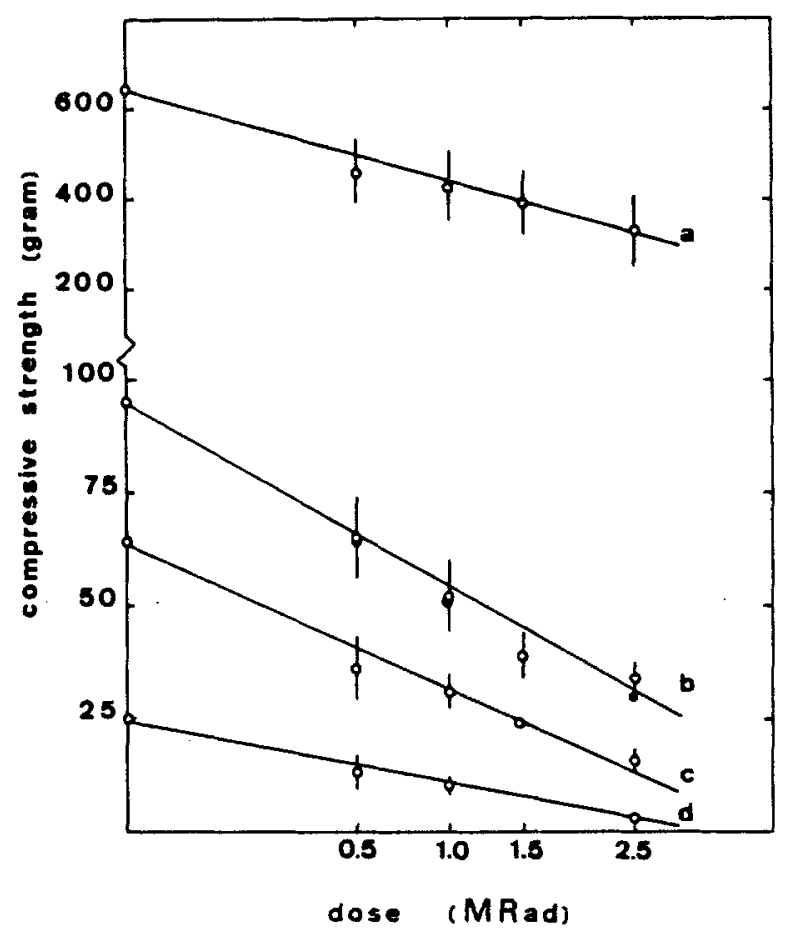

Figure 9. Influence of $\gamma$ radiation on the compressive strength of agarose beads. (a) $4 \%$ agarose powder crosslinked, (b) $6 \%$ gel, (c) $4 \%$ gel, and (d) $2 \%$ gel in the presence of $(0)$ oxygen and $(\bullet)$ in vacuum.

of the capsules and the deformation behavior under compression remain unaltered after steam sterilization. The same results were obtained with beads autoclaved at $134^{\circ} \mathrm{C}$ for $30 \mathrm{~min}$ (Fig. 2).

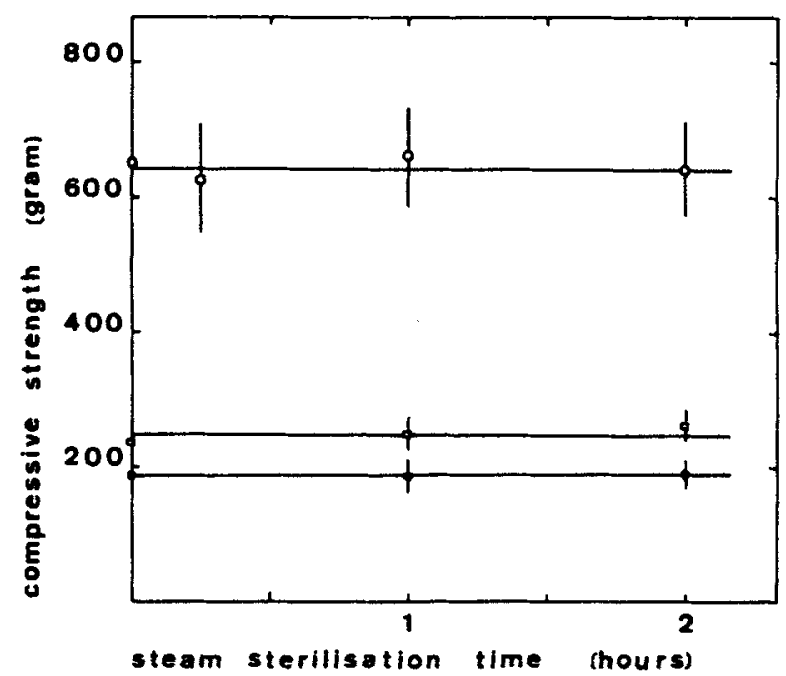

Figure 10. Effects of steam sterilizarion on the compressive strength of agarose $(0)$ beads $4 \%$ and $(\square)$ capsules $33 \%$ activated charcoal and $(0)$ 33\% Imac C12 after crosslinking. 

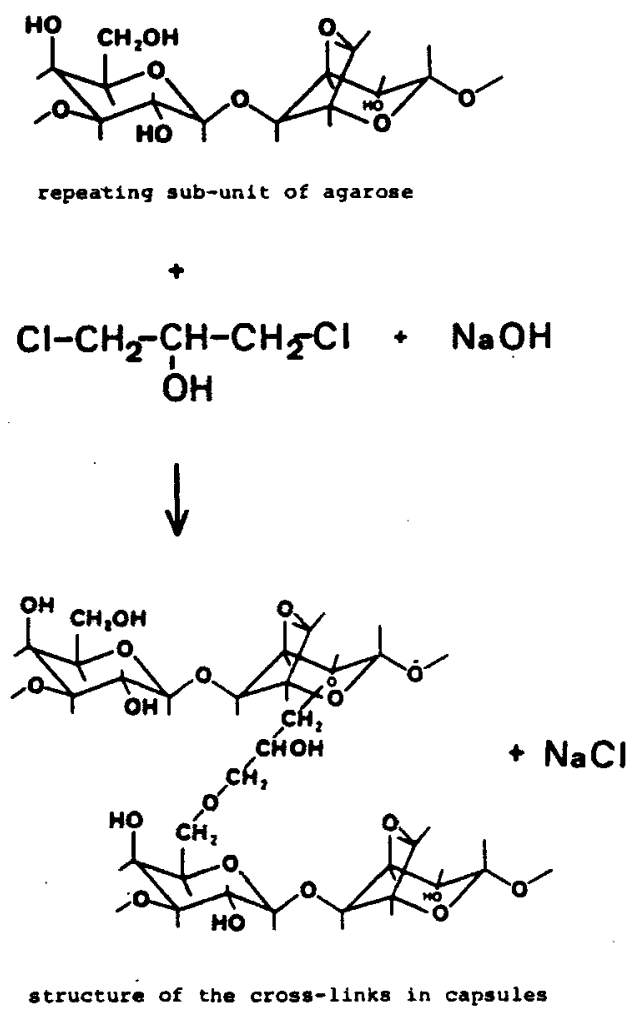

Figure 11. Reaction scheme of the crosslinking reaction.

\section{DISCUSSION}

The method of preparation used provides a convenient route to the encapsulation of sorbents. To the best of our knowledge it is the only technique suitable for the coating of ion-exchange resins. In agreement with Holloway, Harstick, and Brunner ${ }^{4}$ the maximum sorbent content was found to be $33 \mathrm{wt} \%$. For the preparation of capsules with a diameter of 1-3 mm, the optimal agarose concentration was found to be 4 wt. \% as compared with $6 \%$ reported by Holloway, Harstick, and Brunner, ${ }^{4}$ which was found to be correct for larger beads. Since we were interested in small beads, the properties of capsules prepared from $4 \%$ agarose were studied in this work. This implies a reduction in compressive strength which is, however, more than compensated by crosslinking.

The crosslinking reaction is easily performed without particular problems. The reaction occurs by the formation of nonhydrolyzable ether bonds between the agarose hydroxyl group and the halide groups of DCP. The side product, hydrogen chloride, is neutralized by sodium hydroxide according to the reaction scheme shown in Figure 11. This scheme agrees with the observed decrease in $\mathrm{pH}$ during the course of the reaction. A similar reaction has been reported for the crosslinking of Sepharose (agarose) with dibromopropanol as the crosslinking agent. 
The observation that the mechanical strength decreases when the alkaline concentration increases indicates that along with the crosslinking reaction, hydrolysis of agarose proceeds simultaneously. When excesses of $\mathrm{NaOH}$ are used, this phenomenon is even more pronounced. Further support for the occurrence of hydrolysis is the observation that only a markedly reduced compressive strength is observed after prolongation of the reaction time when $\mathrm{NaOH}$ is present in excess.

Encapsulation in agarose significantly improves the blood compatibility, at least in vitro. Typical thrombocyte losses from an in vitro recirculation system using, e.g., citrated blood are 80 and $45 \%$ for native granular Amberlite XAD 4 and activated charcoal, respectively, and 35 and $20 \%$ for agarose encapsulated XAD 4 and charcoal, respectively. ${ }^{8}$

A disadvantage inherent to the encapsulation technique is the loss of adsorptive capacity. Compared with sorbents in their native states, only $25-35 \%$ of the sorbent weight can be employed when the same hemoperfusion cartridges are used. Although the total capacity is reduced, the ultimate rate of adsorption, which is of far more importance, reduces much less dramatically. This effect is due to the use of powdered sorbents. The adsorption kinetics have been studied in vitro in a recirculation system ${ }^{8}$ using methyl orange (M), BSP (B), Vitamin B12 (V), and Inulin (I) as test compounds. The amounts adsorbed after $3 \mathrm{~h}$ recirculation onto agarose encapsulated activated charcoal were $92 \%(\mathrm{M}), 85 \%(\mathrm{~B}), 47 \%(\mathrm{~V})$, and $44 \%$ (I) of the amounts adsorbed onto the native granular charcoal, despite the reduction of the charcoal weight to $25 \%$. These percentages are comparable to those observed for activated charcoal coated with ultrathin membranes of cellulose acetate. ${ }^{9}$ Since the rate of adsorption is related to the diameter of the capsules, we are interested in smaller capsules. These topics relating to adsorption kinetics and blood compatibility have been the subject of a separate publication. ${ }^{8}$

Agarose hydrogels degrade by the influence of $\gamma$ radiation. This behavior is also observed for the parental product agar-agar ${ }^{7}$ and the chemically related cellulose. ${ }^{10}$ Since medical polymers should be resistant to a total dose of at least 5 Mrads, ${ }^{10} \gamma$ irradiation is definitely not a good sterilization technique for this material.

The capsules are, however, not affected by the influence of steam sterilization when crosslinked. The procedures for steam sterilization recommended by the Medical Research Council of the United Kingdom ${ }^{11}$ are above $15 \mathrm{~min}$ at $121^{\circ} \mathrm{C}, 10 \mathrm{~min}$ at $126^{\circ} \mathrm{C}$, and $3 \mathrm{~min}$ at $134^{\circ} \mathrm{C}$. The times used in this study, $120 \mathrm{~min}$ at $122^{\circ} \mathrm{C}$ and $30 \mathrm{~min}$ at $134^{\circ} \mathrm{C}$, are well in excess of these standards. Thus autoclaving provides a good technique for the sterilization of crosslinked agarose. We believe that the crosslinking method described here opens new perspectives for the application of agarose in therapeutic medicine.

We wish to thank J. G. Grolleman for performing some of the experimental work. Finan:ial support was obtained from the Dutch Organization for the Advancement of Pure Research (ZWO-FUNGO). 


\section{References}

1. P. H. Plotz, P. D. Berk, B. F. Scharschmidt, J. K. Gordon, and J. Vergalla, "Removing substances from the blood by affinity chromatography," $I$. Clin. Invest., 53, 778-785 (1974).

2. P. Rawer, H. W. Leber, and G. Schuetterle, "Eine neue Methode zur spezifischen Entfernung toxischer Substancen aus dem Blut," Intensizmed., 15, 59-61 (1978).

3. "Gel filtration; theory and practice," Farmacia Fine Chemicals, Uppsala, Sweden, (1979).

4. C. J. Holloway, K. Harstick, and G. Brunner, "Agarose encapsulated sorbents," Int. I. Artif. Organs, 2, 81-86 (1979).

5. H. Loesgen, G. Brunner, C. J. Holloway, B. Buettelmann, S. Husmann, P. Scharff, and A. Siehoff, "Large agarose beads for extracorporeal detoxification systems," Biomater. Med. Devices Artif. Organs, 6, 151-173 (1978).

6. G. Brunner, K. Harstick, and C. J. Holloway, "Agarose encapsulated adsorbents; a new material for hemoperfusion," in Hemoperfusion, S. Sideman, T. M. S. Chang, Eds., Hemishere, WA, 1980, pp. 37-44.

7. M. Nisizawa, "Studies on irradiation of agar-agar in the solid state," Radiat. Eff., 24, 177-185 (1975).

8. H. W. M. de Koning, R. A. F. M. Chamuleau, and A. Bantjes, "Coating membranes for a sorbent based artificial liver-adsorption characteristics," Artif. Organs, 6, 280-287 (1982).

9. J. Tijssen, A. Bantjes, A. W. J. Van Doorn, J. Feijen, B. Van Dijk, C. R. Vonk, and I. C. Dijkuis, "A hemoperfusion column based on activated carbon granules coated with an ultrathin membrane of cellulose acetate," Artif. Organs, 3, 11-14 (1979).

10. T. Ouwerkerk, "Gamma sterilization of medical plastics," Proc. 3rd Int. Conf. Plastics in Medicine and Surgery, PRI, Enschede, June 21-22 p. 19.1-19.8 (1979).

11. D. F. Williams, "Implants in Surgery," Saunders, London, 1973, p. 245.

Received October 18, 1981

Accepted April 22, 1983 